
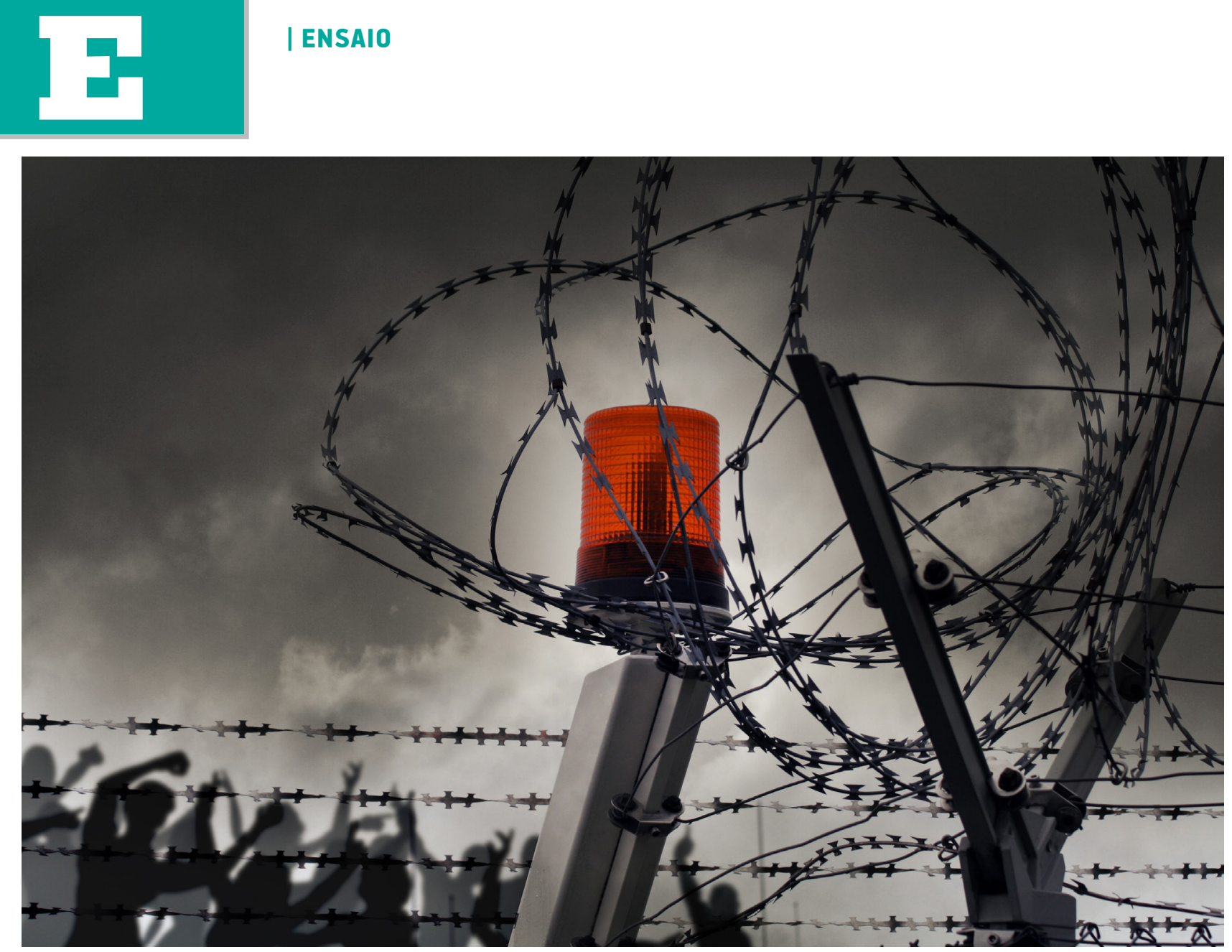

\title{
DIREITOS HUMANOS: \\ UM ASSUNTO TAMBÉM \\ PARA AS EMPRESAS
}

| POR AMON BARROS + FLÁVIA SCABIN + MARCUS VINÍCIUS P. GOMES

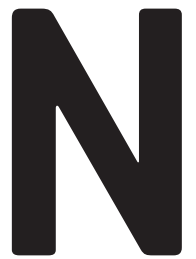

os últimos anos, diversas evidências vieram à tona apontando o envolvimento de empresas blue chip e suas marcas globalmente reconhecidas com práticas de trabalho degradantes, em diferentes estágios de sua cadeia de valor. E não se trata de algo restrito ou esporádico: há ocorrências em diversos setores, como o petrolífero e os de mineração, calçados, alimentos, entre outros. Tanto em casos de trabalho escravo quanto naqueles envolvendo a construção de grandes empreendimentos, a associação entre Direitos Humanos e empresas tem sido cada vez mais presente. No âmbito dos grandes empreendimentos, já são dois os casos brasileiros 


\section{A COBRANÇA DA SOCIEDADE VAI ALÉM DO TRABALHO ESCRAVO, ABARCANDO A RELAÇÃO ENTRE EMPRESAS, SÜAS CADEIAS GLOBAIS E OS IMPACTOS NO MEIO AMBIENTE}

(Belo Monte e Tapajós) sendo analisados pela Comissão Interamericana de Direitos Humanos da Organização dos Estados Americanos (OEA).

$\mathrm{O}$ que também mudou foi o tratamento dado a esses casos. As ações civis públicas propostas contra as usinas hidrelétricas de Belo Monte, Jirau e Santo Antônio já passam de 40, a maioria discutindo os impactos sociais gerados pela sua construção. Além disso, são diversas as condenações pelo Judiciário de corporações envolvidas em condições de trabalho análogas à escravidão. A sentença mais recente, proferida pela Justiça do Trabalho de São Paulo contra a multinacional espanhola Zara, em abril deste ano, pondera a capacidade econômica da empresa para decidir que ela deveria zelar pela retidão de toda a sua cadeia de suprimentos. Esta condenação funciona como um precedente importante.

No âmbito internacional, se originariamente apenas os Estados eram responsabilizados por violações a Direitos Humanos, isso mudou recentemente com a aprovação dos Princípios Orientadores sobre Direitos Humanos e Empresas pelo Conselho de Direitos da Organização das Nações Unidas (ONU). Elaborados a partir de normas preexistentes, os Princípios reúnem parâmetros e instrumentos voltados a garantir que a atuação empresarial se dê em respeito aos Direitos Humanos, orientando a adoção de recursos adequados e eficazes em caso de descumprimento pelas empresas.

O papel da sociedade civil também tem sido expressivo para a construção desse cenário. A cobrança vai além da questão do trabalho escravo para abarcar a relação entre empresas, suas cadeias globais e os impactos no meio ambiente. Vêm sofrendo essa pressão indústrias ligadas às cadeias da carne $\mathrm{e}$ soja no Brasil, à do óleo de palma na Indonésia, entre outras, resultando no desenvolvimento de diferentes mecanismos de governança e reporting. Um exemplo é o sistema de monitoramento desenvolvido por frigoríficos brasileiros como JBS, Marfrig e Minerva, em conjunto com empresas como AgroTools, para monitorar sua cadeia de fornecedores e evitar a compra de gado proveniente de áreas de desmatamento, de invasão de terras indígenas ou de unidades de conservação.

Todas essas pressões se dão em um contexto de expansão dos mercados e aumento do tamanho das organizações. Neste cenário, as empresas são capazes de mobilizar mais recursos a fim de levar a cabo investimentos com potencial de desenvolvimento econômico, mas ao mesmo tempo podem provocar transformações mais profundas no meio ambiente e no tecido social. Isso lhes coloca responsabilidades. As organizações também devem considerar os potenciais danos à sua imagem e os efeitos colaterais que isso pode trazer para além dos custos jurídicos, humanos e financeiros advindos do desrespeito aos Direitos Humanos e sua necessidade de reparação. Muitos stakeholders e stockholders são bastante restritivos em relação a fazer negócios com empresas que tenham acusações de violação de direitos. Exemplos são as barreiras comerciais impostas às organizações que desrespeitam esses direitos ou as posturas das instituições financeiras signatárias dos Princípios do Equador, do Pacto Global ou Fundos Soberanos (especialmente de países europeus). Estes, embora não garantam que violações de direitos ou impactos ambientais não sejam cometidos ao longo de uma cadeia de valor, fornecem parâmetros para que a sociedade civil venha a exercer pressão, causandolhes danos reputacionais, bem como à sua saúde financeira.

Observar os princípios sugeridos pela ONU é um começo interessante, mas cada contexto traz diferentes desafios para a prática empresarial. Neste sentido, o diálogo entre os setores privado e público, tanto para o desenvolvimento de ações quanto para a reflexão sobre suas atuações, é fundamental.

\footnotetext{
PARA SABER MAIS:

Guiding Principles on Business and Human Rights. United Nations Human Rights Office of the High Commissioner: www.ohchr.org/Documents/Publications/ GuidingPrinciplesBusinessHR_EN.pdf. Reporting on Human Rights. Global Reporting Initiative: www. globalreporting.org/resourcelibrary/Reporting-On-HumanRights.pdf.

Corporate Human Rights Reporting, an Analysis of Current Trends. Global Report Initiative: www.globalreporting.org/ resourcelibrary/Human_Rights_analysis_trends.pdf. Just Business: multinational corporations and human rights. John G. Ruggie 2013

AMON BARROS > Professor da FGV-EAESP > amon.barros@fgv.br

FLÁVIA SCABIN > Professora da FGV-EAESP > flavia.scabin@fgv.br

MARCUS VINÍCIUS P. GOMES > Professor da FGV-EAESP > marcus.gomes@fgv.br
} 